\title{
The Using of Honeybee products in Fishery and Apitherapy: A
}

\section{mini review}

\section{Z Selamoglu*}

Department of Medical Biology, Faculty of Medicine, Nigde Ömer Halisdemir University, Campus, 51240, Nigde, Turkey

Received: February 2018

Accepted: April 2018

\begin{abstract}
Many works have emphasized that natural healthy agents have payed attentions nowadays as the mostly used synthetic therapeutics might have some undesirable actions. One can think that some natural nutrients would be better and safer than synthetic ones. Some of these matters, such as natural agents, often show antioxidant effects. These components into natural agents may be helpful to health the of consumers and also to the stabilization of nutrients.
\end{abstract}

Keywords: Honeybee, Fishery, Apitherapy

\section{Introduction}

Due to the presence of various of these compounds such as flavonoids, phenolic acids and their esters in honeybee products and their extracts, if the positive physiological effects and the nontoxicity of the these products are proven it could be used as a mild antioxidant and protective (Talas \& Gulhan 2009; Talas \& Gulhan 2013; Gulhan \& Selamoglu 2016).
Oxidative stress has a big important in field of terrestrial and aquatic toxicology. The Honeybee products and their derivatives have been showed in chemoprevention and drug resistance through inhibition of oxidative stress. Chemical toxic pollutants are major reason of reactive oxygen species (ROS) in living organisms. Membrane phospholipids of aerobic systems are permanently caused to oxidant forces from endogenous and exogenous factors, while peroxidized membranes and lipid peroxidation products perform chronic threats to aerobic cells. The basic antioxidant protection against free radical and ROS is done by the enzymes glutathione peroxidase, superoxide dismutase and catalase, respectively. The nonenzymatic antioxidant systems are basicly substances of low molecular weight, such as vitamins $\mathrm{C}$ and $\mathrm{E}$, urate, retinyl esters, $\beta$-carotene, glutathione, etc. Honeybee products could inhibit destroy to the unsaturated fatty acid of subcellular membranes by lipid peroxidation induced by

* Correspondence Z Selamoglu, Department of Medical Biology, Faculty of Medicine, Nigde Ömer Halisdemir University, Campus, 51240, Nigde, Turkey (e-mail: zselamoglu@ohu.edu.tr). 
free radicals in fish (Talas \& Gulhan 2009; Talas \& Gulhan 2013; Gulhan \& Selamoglu 2016).

Honeybee products and its derivatives are well-known to be free radical scavengers and antioxidants. Natural antioxidants are mostly consumed as additional food to modulate oxidative stress in living organisms. Honeybee products have an important in clinical interest due to their favourable pharmacological and biological activities. Many phytochemical classes, such as flavonoids, aromatic acids and phenolic compounds have been attributed to the healthy properties of these components. Bioflavonoids, the effective components in some honeybee products and plants, are antioxidant agents. Also, the bioflavanoid content is recently taking attention. Antioxidants stop oxidative chain reactions by declined free radical molecules, and prevent various oxidation reactions. (Selamoglu 2017a,b). Honeybee products are one of these natural matters. Various phenolic components such as propolis, pollen, honey and royal jelly have the antioxidant capability. The paper presents main information on the consume of the honeybees products in the apitherapy.

\section{Discussion}

Nowadays, there have been a great deal of works made on using of the honeybees products in the apitherapy field. In most of these studies the products of honeybees were given to fish in propolis and pollen, forms.

In results of some works have been reported that propolis has a great support to antioxidative systems in some tissues of rainbow trout. The beneficial of propolis to inhibit the oxidative stress induced by pesticide in fish was rationalized (Gulhan, Duran, Selamoglu Talas, Kakoolaki \& Mansouri 2012; Kakoolaki, Selamoglu Talas, Cakir, Ciftci \& Ozdemir 2013; Gulhan, Selamoglu Talas, Erdogan, Orun 2014a; Aldemir, Selamoglu Talas, Gulhan, Cakır, Durna Dastan \& Dogan 2014; Orun, Dogru, Erdogan, Dogru, Ongun, Yuksel \& Talas Selamoğlu 2014).

In other studies have been reported that pollen has an significant effect to antioxidative system in various tissues of rainbow trout (Gulhan, Akgul, Dastan, Durna Dastan \& Selamoglu Talas 2014b; Durna Dastan, Dastan, Gulhan, Kirkbes \& Selamoglu Talas 2014; Selamoglu, Durna Dastan, Gulhan, Dastan \& Erdemli 2015; Durna Dastan, Gulhan, Selamoglu \& Dastan 2017).

Fish is one of the most precious aquatic organisms which can produce important sources of protein for human nutrition. Fish and fishery products have been implied as nutritional sources because of their high protein and unsaturated fatty acid levels. The honeybees products could inhibit destroy to the unsaturated fatty acid of subcellular membranes by lipid peroxidation caused by free radicals.

Some investigations claim a direct evidence for the protective action of the honeybees products on the antioxidative defense system against toxic agents such as heavy metals (Orun, Dogru, Erdogan, Dogru, Ongun, Yuksel \& Talas Selamoğlu 2013; Gulhan \& Selamoglu 2016). In various researches, with apply of propolis, the toxic activities of arsenic have prevented significantly in some tissues of carp. 
(Selamoglu Talas, Dundar, Gulhan, Orun \& Kakoolaki 2012; Selamoglu Talas, Gulhan, Erdogan \& Orun 2014; Selamoglu, Duran, Gulhan \& Erdemli 2015). This might be related to the fact that toxic agents are detoxicated by propolis, which thus enabled fish exposed to toxic materials to live. Finally, honeybee products are precious matters for research on antioxidative effects.

In the recent years, substances of natural origin have been gaining more and more attention as a source of biologically active compounds. For centuries people have known their properties e.g., antibacterial, antifungal, anti-inflammatory antioxidant properties and anticancer. Among many others those compounds include honeybee products, propolis and pollen in particular. From more than aromatic esters present in honeybee products, the most promising pharmacological effect can be observed in the case of polyphenols, while the presence of a hydroxyl group in the catechol ring is largely responsible for unique biological properties of them. Honeybee products are a commonly available dietary supplement used both by healthy and ill human and animals. Flavonoids are effective antioxidants, free radical inhibitors, and metal chelators: these compounds supress lipid peroxidation and represent different biological effects.

\section{Conclusion}

Recently, researchers have turned their attention towards the use of dietary supplements with antioxidant capacities. Honeybee products such as propolis, pollen, honey and royal jelly have the antioxidant capability that show various biological properties, including antioxidant activity. Now, using of beneficial agents and safe nutrients has obtained significant actually in the developed countries, as society awareness focused on human, animal and environmental health. Mostly when examined analyses on honeybee components used for antioxidant cure, the data are demonstrated that the phenolic components are intensively. Such products have potent antioxidant capacity and are used as natural protectors.

\section{References}

Aldemir O.S., Selamoglu Talas Z., Gulhan M.F., Cakır O., Durna Dastan S. \& Dogan H. (2014) Role of Propolis on Oxidative Stress in Various Tissues of Fish. Fresenius Environmental Bulletin, 23 (12c), 3546 3550.

Durna Dastan S., Dastan T., Gulhan M.F., Kirkbes A. \& Selamoglu Talas Z. (2014) Biochemical changes in muscle and gill tissues of rainbow trout treated with various concentrations of pollen extract. Research Opinions in Animal \& Veterinary Sciences, 4(10), 540-544.

Durna Dastan S., Gulhan M.F., Selamoglu S. \& Dastan T. (2017) The determination of different effective concentration of ethanolic extract of bee pollen on biochemical analysis in liver, spleen and heart tissues of rainbow trout, Oncorhynchus mykiss (Walbaum, 1792). Iranian Journal of Fisheries Sciences, 16(1), 326-340. 
Gulhan M.F., Duran A., Selamoglu Talas Z., Kakoolaki S. \& Mansouri S.M. (2012) Effects of Propolis on microbiologic and biochemical parameters of Rainbow trout (Oncorhynchus mykiss) after exposure to the pesticide. Iranian Journal of Fisheries Sciences, 11(3), 490-503.

Gulhan M.F., Selamoglu Talas Z., Erdogan K., Orun I. (2014a) The Effect of Propolis on Gill, Liver, Muscle Tissues of Rainbow Trout (Oncorhynchus mykiss) Exposed to Various Concentrations of Cypermethrin. Iranian Journal of Fisheries Sciences, 13(3), 684-701.

Gulhan M.F., Akgul H., Dastan T., Durna Dastan S. \& Selamoglu Talas, Z. (2014b) Effects of different concentrations of pollen extract on brain tissues of Oncorhynchus mykiss. Journal of Coastal Life Medicine, 2(3), 169-174.

Gulhan M.F. \& Selamoglu Z. (2016) Comparison of the effects of propolis and pollen extracts in the same concentrations on some biochemical and hematological parameters in rainbow trout (Oncorhynchus mykiss). Journal of Survey in Fisheries Sciences, 3(1), 1-8.

Kakoolaki S., Selamoglu Talas Z., Cakir O., Ciftci O. \& Ozdemir I. (2013) Role of Propolis on Oxidative Stress in Fish Brain. Basic and Clinical Neuroscience, 4(2), 45-50.

Orun I., Dogru M.I., Erdogan K., Dogru A., Ongun A., Yuksel E. \& Talas Selamoğlu Z. (2013) Effects of acute and chronic exposure to glyphosate on common carp (Cyprinus carpio
L.) hematological parameters: The beneficial effect of propolis. Fresenius Environmental Bulletin, 22(9), 2504-2509.

Orun I., Selamoglu Talas Z., Gulhan M.F. \& Erdogan K. (2014) Role of propolis on biochemical and hematological parameters of Oncorhynchus mykiss exposed to cypermethrin. Survey in Fisheries Sciences, 1(1), 21-35.

Selamoglu Talas Z., Dundar S.P., Gulhan M.F., Orun I. \& Kakoolaki S. (2012) Effects of propolis on some blood parameters and enzymes in carp exposed to arsenic. Iranian Journal of Fisheries Sciences, 11(2), 405- 414.

Selamoglu Talas, Z., Gulhan M.F., Erdogan K. \& Orun, I. (2014) Antioxidant effects of propolis on carp (Cyprinus carpio) exposed to Arsenic: Biochemical and histopathologic findings. Diseases of Aquatic Organisms, 108, 241-249.

Selamoglu Z., Duran A., Gulhan M.F. \& Erdemli M.E. (2015) Effects of propolis on biochemical and microbiological parameters in carp (Cyprinus carpio) fillets exposed to arsenic. Iranian Journal of Fisheries Sciences, 14(4), 896-907.

Selamoglu Z., Durna Dastan S., Gulhan M.F., Dastan T. \& Erdemli M.E. (2015) The Effects of Ethanolic Pollen Extract in Various Concentrations on Total RNA and Total Protein Levels in Different Tissues of Rainbow Trout (Oncorhynchus mykiss). Analele Științifice ale Universităţii “Alexandru Ioan Cuza” din Iași, s. Biologie animală, Tom LXI, 5-10. 
Selamoglu Z. (2017a) Polyphenolic Compounds

in Human Health with Pharmacological Properties. Journal of Traditional Medicine \& Clinical Naturopathy, 6(4), e 137.

Selamoglu Z. (2017b) Honeybee Pollen with Health Beneficial: An Update. Journal of Traditional Medicine \& Clinical Naturopathy, 7(1), e141.

Talas Z.S. \& Gulhan M.F. (2009) Effects of Various Propolis Concentrations on
Biochemical and Hematological Parameters of Rainbow Trout (Oncorhynchus mykiss). Ecotoxicology and Environmental Safety, 72, 1994-1998.

Talas Z.S. \& Gulhan M.F. (2013) Effects of various pollen concentrations on some biochemical and hematological parameters and paraoxanase activity in Rainbow trout (Oncorhynchus mykiss). Iranian Journal of Fisheries Sciences, 12(4), 928-937. 